\title{
Corrigendum to "Dielectric relaxation of near-percolated carbon nanofiber polypropylene composites" [Physica B: Phys. Condens. Matter 516C (2017) 41-47]
}

\author{
A.J. Paleo ${ }^{a, *}$, A. Zille ${ }^{\mathrm{a}}$, F.W. Van Hattum ${ }^{\mathrm{b}}$, A. Ares-Pernas ${ }^{\mathrm{c}}$, J. Agostinho Moreira ${ }^{\mathrm{d}}$ \\ a 2C2T - Centro de Ciência e Tecnologia Têxtil, Universidade do Minho, Campus de Azurém, 4800-058, Guimarães, Portugal \\ ${ }^{\mathrm{b}}$ Saxion University of Applied Sciences, Research Center Design and Technology, M.H. Tromplaan 28, Postbus 70.000, 7500 KB, Enschede, Netherlands \\ c Universidade da Coruña, Grupo de Polímeros, Centro de Investigacións Tecnolóxicas, Campus de Ferrol, 15471, Ferrol, Spain \\ d IFIMUP and IN-Institute of Nanoscience and Nanotechnology, Department of Physics and Astronomy, Faculty of Science, University of Porto, Rua do Campo Alegre, \\ 687, 4169-007 Porto, Portugal
}

The authors have found an error in the FTIR analysis of our paper. The corrected Fig. 2 and its new discussion are provided in this corrigendum. References 30 and 31 remain unaltered and they can be consulted in the original paper. The authors would like to apologise for any inconvenience caused.

Infrared spectroscopy is a widely used characterization technique to elucidate the structure and interactions in different materials, including polymer composites. Fig. 2 presents the spectra of $\mathrm{PP}$ in comparison with the samples filled with $0.9,1.4$ and $1.9 \mathrm{vol} \%$ of CNF. Neat PP spectrum shows the characteristic bands assigned to asymmetric and symmetric stretching vibrations of methyl and methylene groups in the 3000-2750 $\mathrm{cm}^{-1}$ region and to the $\mathrm{CH}_{3}$ asymmetric and symmetric bending between 1455 and $1375 \mathrm{~cm}^{-1}$ [30]. Other noticeable bands are located at $1166 \mathrm{~cm}^{-1}$ and $1044 \mathrm{~cm}^{-1}$ assigned to $\mathrm{CH}_{2}$ twisting and $\mathrm{CH}$ wagging vibration and to $\mathrm{C}-\mathrm{C}$ chain stretching vibration, respectively. The bands at $998 \mathrm{~cm}^{-1}$ and $973 \mathrm{~cm}^{-1}$ are assigned to $\mathrm{CH}$ bending and wagging vibration and $\mathrm{CH}_{3}$ rocking vibration and to $\mathrm{CH}_{3}$ rocking, $\mathrm{CH}_{2}$ wagging and $\mathrm{CH}$ bending vibrations, respectively. Finally, the band at $898 \mathrm{~cm}^{-1}$ is assigned to $\mathrm{C}-\mathrm{C}$ chain symmetric stretching vibration, the band at 840 $\mathrm{cm}^{-1}$ to $\mathrm{CH}_{2}$ rocking and $\mathrm{C}-\mathrm{CH}_{3}$ stretching vibrations and the band at $809 \mathrm{~cm}^{-1}$ to $\mathrm{C}-\mathrm{C}$ chain symmetric stretching vibration and $\mathrm{CH}_{2}$ rocking vibration [31]. After the addition of the CNF to the system is possible to confirm that the peaks previously described and assigned to the polypropylene remain unchanged after the addition of CNF in 0.9, 1.4 and 1.9 vol \% PP/CNF composites, though it is possible to observe a decreasing of their intensity peaks as function of CNF loading.
Furthermore, another decreasing of transmittance in the region from 750 to $500 \mathrm{~cm}^{-1}$ is found for PP/CNF composites, thus indicating the contribution from the CNF.

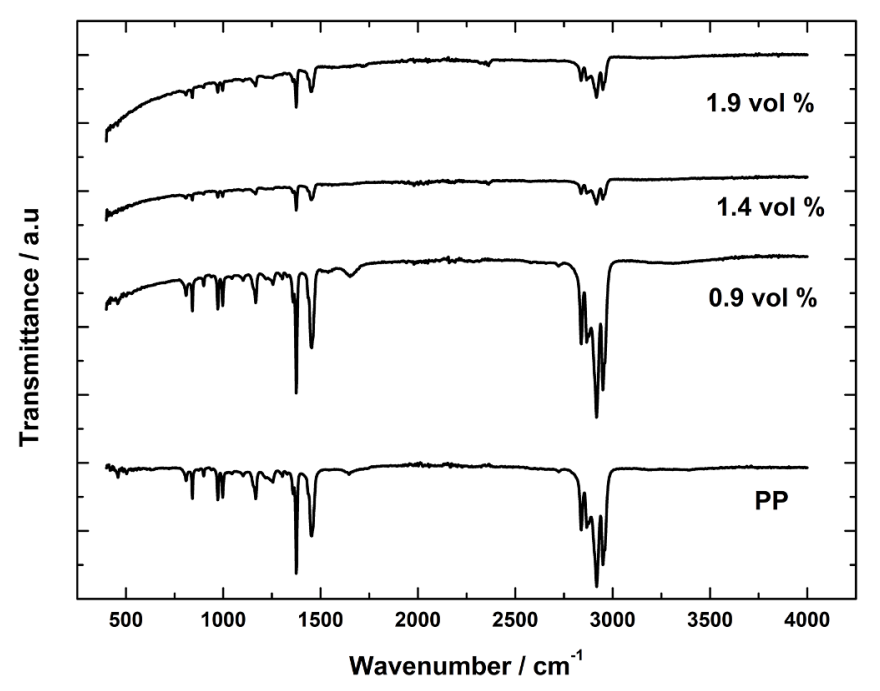

Fig. 2. (Corrected) Infrared spectra of PP and PP/PR 25 PS XT composites.

DOI of original article: https://doi.org/10.1016/j.physb.2017.04.027.

* Corresponding author.

E-mail addresses: ajpaleovieito@2c2t.uminho.pt, antonio.paleo.vieito@gmail.com (A.J. Paleo). 